\title{
Ultrasonic-assisted extraction of gallic acid and isoquercetin from aspergillus niger fermented tri-phala waste
}

\author{
Teerin Chysirichote ${ }^{1,}$ and Pattarabhorn Pakaweerachat ${ }^{1 *}$ \\ ${ }^{1}$ Department of Food Engineering, Faculty of Engineering, King Mongkut's Institute of Technology Ladkrabang, Bangkok, Thailand
}

\begin{abstract}
The Aspergillus niger fermented Tri-phala waste (FTW) was extracted with ultrasonic assisted extraction (UAE) using deionized water as an extraction medium at $30^{\circ} \mathrm{C}$. The $40 \mathrm{kHz}$ ultrasonic frequency was used for sonicate the FTW immerged in the water at the ratio of $1: 100$ for 10, 20, 30, 40, 50 and $60 \mathrm{~min}$. The contents of gallic acid, isoquercetin obtained after extraction were measured by HPLC. The extraction yields of gallic acid and isoquercetin were compared with the yields from the water extraction without ultrasonic assistance (control condition). The results showed that using the ultrasonic assistance increased the extraction yield of gallic acid from $0.25 \pm 0.03$ to $1.26 \pm 0.25 \mathrm{~g} \mathrm{~g}^{-1}$ with the shorter extraction time from $60 \mathrm{~min}$ to $30 \mathrm{~min}$. Moreover, isoquercetin extraction yield increased from $0.17 \pm 0.02$ to $0.41 \pm 0.04 \mathrm{~g} \cdot \mathrm{g}^{-1}$ with the shorter extraction time from $60 \mathrm{~min}$ to $20 \mathrm{~min}$.
\end{abstract}

\section{Introduction}

Tri-phala is a traditional Ayurvedic herbal medicine, consisted of equal parts of three herbal fruits: Indian gooseberry (Emblica officinalis Gaertn), Myrolan Wood (Terminutesalia chebula Retz.) and Belleric myrobalan (Terminutesalia bellerica (Gaertn) Roxb) [1-3]. Typically, Tri-Phala is boiled in water to extract the polyphenolic compounds which are gallic acid and rutin $[4,5]$. Both of them have powerful antioxidant properties used in medical applications such as antimutagenic, lipid-lowering and anti-tumor agent [6-8]. Charoenchai et al. [4] measured gallic acid and rutin in Tri-phala powder using HPLC as $1.32-4.02 \%$ and $0.61-2.94 \%$ $(\mathrm{w} / \mathrm{w})$, respectively. However, Pawar and Alunkhe [5] measure gallic acid and rutin using UV Spectrophotometor as $0.67 \pm 0.01$ and $0.76 \pm 0.01$ in Triphala powder, respective.<smiles>O=C(O)c1cc(O)c(O)c(O)c1</smiles>

Fig. 1 Gallic acid [9]

Recently, Pattarabhorn and Teerin [2] studied the solid state fermentation (SSF) of $A$. niger on Triphala waste and found the gallic acid as the main product and a trace of isoquercetin (data not shown). Isoquercitrin is a kind of flavonoid which is derived from rutin [5]. Isoquercetin is an active ingredient that posesses many medical properties such as antioxidant, atheroprotective, allelopatic, plaque-stabilizing and anti-inflammatory [10-12] and has been in the GRAS (general regarded as safe) standard to be used as food additive.<smiles>O=c1c(OC2OC3C(O)C(O)C(O)C(O)C(O)C(O)C3O2)c(-c2ccc(O)c(O)c2)oc2cc(O)cc(O)c12</smiles>

Fig. 2 Isoquercetin [13]

Gallic acid and isoquercetin are bioactive compounds that are soluble in water due to their strong electronegativity. The samples of bioactive compound extraction are shown in table 1.

Ultrasonic-assisted extraction has been well proven as a green technology and has enhanced the extraction process in different green aspects. Its advantages over other extraction methods are reducing extraction time, solvent usage, and energy consumption, increasing a yield of production, and enhancing bioactivity preservation of the separated biomolecules due to lower extraction temperatures [14]. Altemimi et al. [15] found that $50 \%$ ultrasonic power, frequency $37 \mathrm{kHz}$ with extraction time $30 \mathrm{~min}$ at $40{ }^{\circ} \mathrm{C}$ increased the extraction yield, total phenols, flavonoids, DPPH-free radical 
scavenging activity and \% ferric reducing antioxidant power in spinach extracts. Corrales et al. [16] also reported that ultrasonic enhanced anthocyanin extraction from grape by-products by disrupting its cell wall.

Table 1. Contents of isoquercetin and gallic acid extracted from different materials

\begin{tabular}{|c|c|c|c|}
\hline Materials & Isoquercetin & Gallic acid & References \\
\hline Apple juice & $4.81 \pm 0.95 \mathrm{mg} \mathrm{L}^{-1}$ & - & {$[17]$} \\
\hline Scutia buxifolia & $6.66 \pm 0.04 \mathrm{mg} \mathrm{L}^{-1}$ & - & {$[18]$} \\
\hline $\begin{array}{c}\text { Leaves } \\
\text { (Morus nigra } \text { L.) }\end{array}$ & $1.84 \mathrm{mg} \mathrm{g}^{-1} \mathrm{dw}$ & - & {$[19]$} \\
\hline Ardisia japonica & $0.09 \mathrm{mgg}^{-1}$ & $2.15 \mathrm{mgg}^{-1}$ & {$[20]$} \\
\hline $\begin{array}{c}\text { Stem bark } \\
\text { (jatropha curcas) }\end{array}$ & - & $0.54 \mathrm{mg} \mathrm{L}^{-1}$ & {$[21]$} \\
\hline $\begin{array}{c}\text { Leaves (Suaeda } \\
\text { glauca } \text { Bge.) }\end{array}$ & - & $6.30 \mathrm{mgg}^{-1}$ & {$[22]$} \\
\hline
\end{tabular}

Therefore, we were interested to increase the gallic acid and the isoquercetin yields during water extraction of the FTW by the ultrasonic assistance. The objective of this study was to compare the extraction rates and yields of gallic acid and isoquercetin released from the FTW by $A$. niger with the UAE and the water extraction.

\section{Materials and methods}

\subsection{Materials preparation}

TW was dried at $60{ }^{\circ} \mathrm{C}$ in a tray dryer for $24 \mathrm{~h}$ and ground using a hammer mill. The particles were screened using 30-mesh and 70-mesh sieves using a sieve shaker to obtain the particles size between 210 595 micron for the SSF [2]. The screened particles were adjusted their moisture content to $55 \%(\mathrm{w} / \mathrm{w})$ using $0.75 \%$ sodium nitrate solution, which was used as a nitrogen source, and sterilized at $120^{\circ} \mathrm{C}$ for $20 \mathrm{~min}$. Then, the spores of $A$. niger were inoculated at the concentration of $5 \times 10^{5}$ spores $\cdot \mathrm{g}^{-1}$ of dry substrate. The SSF were conducted in $250 \mathrm{~mL}$ Erlenmayer flask containing the substrate $30 \mathrm{~g}$ at $30{ }^{\circ} \mathrm{C}$ for $72 \mathrm{~h}$. The fermented sample (FTW) was dried at $60{ }^{\circ} \mathrm{C}$ in a hot-air oven for $24 \mathrm{~h}$ and milled into a powder for the extraction.

\subsection{Gallic acid and Isoquercetin Extraction}

The FTW was sonicated for 10, 20, 30, 40, 50 and $60 \mathrm{~min}(40 \mathrm{kHz})$ at $30{ }^{\circ} \mathrm{C}$ to extract the gallic acid and isoquercetin. Control sample was prepared by soaking sample into deionized water at $30^{\circ} \mathrm{C}$ for $10,20,30,40$, 50 and $60 \mathrm{~min}$. The temperature was controlled by a temperature controller and monitored all the extraction time. In case that the temperature was over than $30^{\circ} \mathrm{C}$, cold water was added into the baht. The extraction rate was calculated from a slope of a time course curve of an extraction in a unit of $\mathrm{g}^{\cdot} \mathrm{g}^{-1} \cdot \mathrm{min}^{-1}$.

\subsection{Gallic acid and isoquercetin determination}

HPLC system with the Water 717 plus autosampler was used to carry out the analysis. The mobile phase was the gradient of acetonitrile and acetic acid $(0.1 \%)$ in water. The flow rate was $1 \mathrm{~mL} \cdot \mathrm{min}^{-1}$ and a detection was at $280 \mathrm{~nm}$. The column was phenomenex and the injection volume was $10 \mu \mathrm{L}$ [2]. The gallic acid and isoquercetin contents were reported as a gram of gallic acid and isoquercetin per one gram of dry FTW. The chromatogram of the extracted FTW was shown in figure 3. The first and second peak represent gallic acid and isoquercetin, respectively.

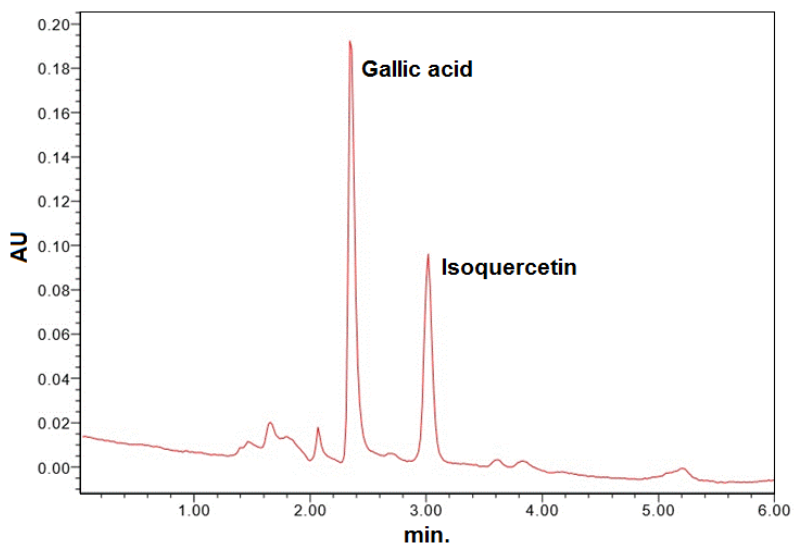

Fig. 3 Chromatogram of the FTW extracted.

\subsection{Data analysis}

The experiment was carried out in triplicate. An average values \pm standard deviations were reported as results. Analysis of variance (ANOVA) at the $95 \%$ significance level was used to analyse the significance of data.

\section{Results and discussion \\ 3.1 Gallic Acid Extraction}

Figure 4 shows that the highest extraction rates obtained from both the UAE and the water extraction (control) were found from 0 to $30 \mathrm{~min}$ as $0.42 \pm 0.00$ and $0.01 \pm 0.00 \mathrm{~g}^{-1} \mathrm{~g}^{-1} \mathrm{~min}^{-1}$, respectively.

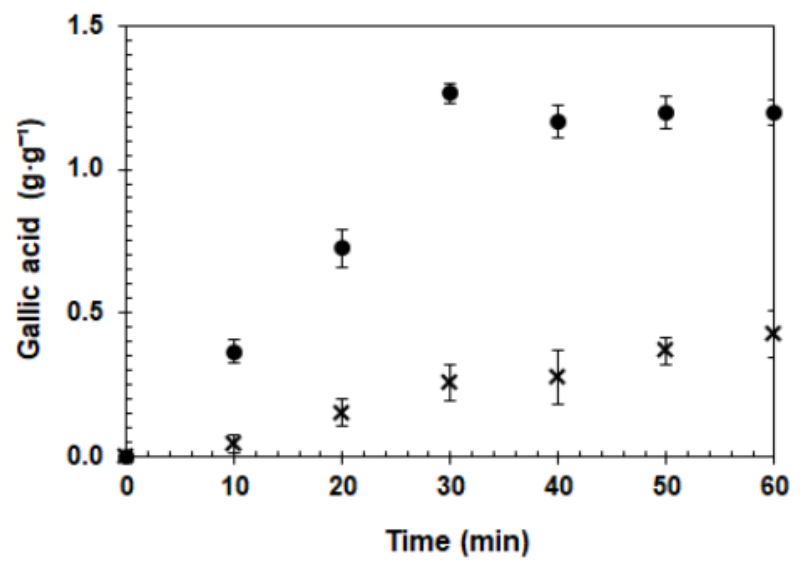

Fig. 4 Gallic acid content of control ( $\times$ ) and UAE (•) during the extraction

The maximum content of gallic acid released from the UAE was $1.26 \pm 0.25 \mathrm{gg}^{-1}$ after $30 \mathrm{~min}$. extraction, while the highest one from the water extraction (control) 
was only $0.25 \pm 0.03 \mathrm{gg}^{-1}$ after $60 \mathrm{~min}$ extraction. It was believed that the releasing gallic acid in the UAE after $30 \mathrm{~min}$. was occurred due to the equilibrium of the gallic acid concentration in the solution and the extracted FTW. The UAE helped shorten this extraction process since a violent shockwave from a sonication disrupted the substrate cell wall to allow solvent penetrating into the cell and extracting the desired component [23]. However, when using high frequencies and power of ultrasonic treatment caused a degradation or an oxidation of the phenolic compounds by the generation of highly reactive hydroxyl radicals [24].

\subsection{Isoquercetin Extraction}

The yield of isoquercetin from the FTW during the UAE and control water extraction was shown in figure 5 . It is indicated that the isoquercetin releasing from the FTW in the UAE process highly increased from 0 to 20 min extraction. In contrast, that in the water extraction without sonicate-assisted (control) slowly increased until $60 \mathrm{~min}$ or the end of the study period. The highest yield of isoquercetin from the UAE was found at $20 \mathrm{~min}$ as $0.41 \pm 0.04 \mathrm{~g} \mathrm{~g}^{-1}$ which could be calculated the extraction rate as $0.02 \pm 0.00 \mathrm{gg}^{-1} \mathrm{~min}^{-1}$. In comparison, the isoquercetin in the control extraction gradually released from the FTW until a terminal of study period (60 min). Its maximum yield measured at $60 \mathrm{~min}$ was only

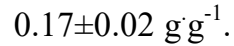

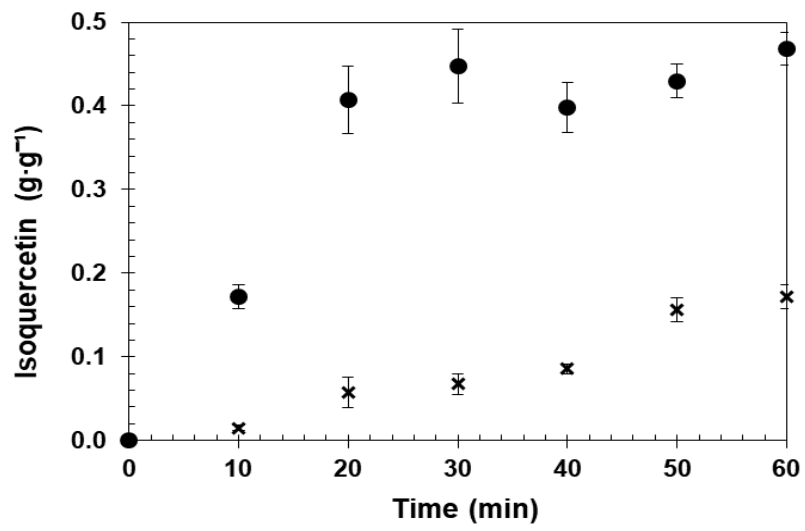

Fig. 5 Isoquercetin content of control $(x)$ and UAE $(\bullet)$ during the extraction

\section{Conclusion}

The water extraction of $A$. niger fermented TW with ultrasonic-assisted increased the extraction yields of gallic acid and isoquercetin. It also reduced the extraction time down to $30 \mathrm{~min}$ for gallic acid and 20 min for isoquercetin to obtain their highest yields.

\section{Acknowledgements}

The authors would like to thank you for the financial support from the National Research Council of Thailand and the Institute of Thai Traditional Medicine, Department for Development of Thai Traditional Medicine and Alternative Medicine, Ministry of Public Health, Thailand for provided the facilities to carry out this research.

\section{References}

1. D. Frawley. Ayurvedic healing, a comprehensive guide, (Montilal Banarsidass, New-Delhi, 2003)

2. P. Pakaweerachat, T. Chysirichote, Proceeding of The 9th TSAE International Conference, Bankok 70 (2016)

3. N. Birla, K. Das Prabhat, Pharm. Biol. Eval. 3, 366 (2016)

4. L. Charoenchai, P. Pathompak, F. Madaka, S. Settharaksa, W. Saingam, BHST. 14, 57 (2016)

5. N. P. Pawar, V. R. Salunkhe, Int J Pharmtech Res. 5, 724 (2013)

6. X. Q. Lin, F. Li, Y. Q. Pang, H. Cui, Anal. Bioanal. Chem. 378, 2028 (2004)

7. X. W. Yu, Y. Q. Li, S. M. Zhou, Y. Y. Zheng, World J. Microbiol. Biotechnol. 23, 1091 (2007)

8. R. Jasuja, F.H. Passam, D.R. Kennedy , S.H. Kim, L.V. Hessem, L. Lin, S.R. Bowley, S.S. Joshi, J.R. Dilks, B. Furie, B.C. Furie, R. Flaumenhaft, J. Clin. Invest. 6, 2104 (2012)

9. B. Badhani, N. Sharma, R. Kakkar, RSC Adv. 35, 27540 (2015)

10. K. Motoyama, H. Koyama, M. Moriwaki, K. Emura, S. Okuyama, E. Sato, M. Inoue, A. Shioi, Y. Nishizawa, Nutrition, 4, 421 (2009)

11. E. 1. Salim, M. Kaneko, H. Wanibuchi, K. Morimura, S. Fukushima, Food Chem. Toxicol. 12, 1949 (2004)

12. J. Fernandez, R. Reyes, H. Ponce, M. Oropeza, M. Vacalsteren, C. Jankowski, M. G. Campos, Eur. J. Pharmacol. 522, 108 (2005)

13. J. C. R. Vellosa, L. O. Regasini, N. M. Khalil, V. D. S. B. Bolzani, O. A. K. Khalil, F. A. Manente, H. P. Netto, O. M. M. F. Oliveira, Eclet. Quím. 36 (2011) Doi : 10.1590/S0100-46702011000200001

14. I. Alzorqi, S. Sudheer, T. J. Lu, S. Manickam, Ultrason. Sonochem. 35, 531 (2017)

15. A. Altemimi, R. Choudhary, D.G. Watson, Ultrason. Sonochem., 24, 247 (2015)

16. M. Corrales, S.Toepfl, P. Butz, D. Knorr, B. Tauscher, Innov. Food Sci. Emerg. Technol. 9, 85 (2008)

17. V. B. Suarez, J. Santamaria Victorero, J.J. Mangas Alonso, D. Blanco Gomis, J. Agric. Food Chem. 42, 2732 (1994)

18. B. Aline Augusti, S. Michele Rorato, M. Luiz Filipe, F. Olmiro de Souza, M. Michel Mansur, M. C. Ivana Beatrice, A. Margareth Linde, Molecules. 17, 5757 (2012)

19. M. M. Freitas, F. Pedro Ribeiro, S. Paula Monteiro, F. Christopher William, S. G. Eliete Neves, M. Yanna Karla, S. Damaris, F. B. Yris, S. Luiz Alberto, M. Mauri, M. Perola, PLOS ONE. 11 (2016). Doi:10.1371/journal.pone.0163130

20. X. Yu, J. Teye Azietaku, J. Li, H. Wang, F. Zheng, J. Hao,Y. Chang, , Evid Based Complement. Alternat. Med. (2018). Doi:10.1155/2018/4964291

21. D. M. Amirah Reddy Prasad, R. Maksudur Khan, J. Appl. Sci. 12, 1106 (2012) 
22. X. H. Wang, C. Cai, X. M. Li, Optimal Extraction of Gallic Acid from Suaeda glauca Bge. Leaves and Enhanced Efficiency by Ionic Liquids, Int. J. Chem. Eng., (2016) .Doi: 10.1155/2016/5217802

23. S. Hemwimol, P. Pavasant, A. Shotipruk, Ultrason. Sonochem. 13, 543 (2006)

24. L. Galvan D'Alessandro, K. Kriaa, I. Nikov, K. Dimitrov, Ultrasound assisted extraction of polyphenols from black chokeberry, Sep. Purif. Technol, 93, 42 (2012) 